Article

\title{
Gendered Career Pathways among Doctoral Graduates in the United Kingdom
}

\author{
Nitzan Peri-Rotem \\ Department of Sociology, Philosophy and Anthropology, University of Exeter, Clayden, Streatham Rise, \\ Exeter EX4 4PE, UK; n.peri-rotem@exeter.ac.uk
}

Received: 29 July 2019; Accepted: 12 November 2019; Published: 16 November 2019

\begin{abstract}
While women form about half of PhD students in Western countries, previous studies have shown that female doctoral graduates are underrepresented in senior positions and have lower earnings compared to their male counterparts within and outside academia. Less is known however about the role of gender in determining the odds of securing a permanent position among doctorate recipients. In this study, we use data from the UK Doctoral Impact and Career Tracking Survey from 2013 to explore the career trajectories of doctoral graduates within seven to nine years after earning their degree. We find that in every observed time point following graduation (0.5, 3.5, and 7-9 years), men are significantly more likely to work in a permanent job than women are. Furthermore, gender gaps in permanent employment are particularly pronounced in the private sector and in non-academic occupations. Using a nested logistic regression model, we find that the higher propensity of female doctoral graduates to work in part-time employment compared to their male counterparts, in combination with other differential employment characteristics has cumulative negative implications on their likelihood of securing a permanent position.
\end{abstract}

Keywords: gender; higher education; doctoral graduates; job security; family-work balance

\section{Introduction}

Across the developed world, the proportion of women obtaining tertiary education has increased markedly over the past decades. Thus, in many Western countries, including the United Kingdom, the proportion of degree-educated women currently exceeds that of men (Van Bavel 2012). A similar increase occurred among PhD students, as women now form nearly half of $\mathrm{PhD}$ graduates across Europe (European Commission 2019). Despite these advances towards gender equality in higher education, women are still underrepresented in senior positions, both in academia and in other sectors (Blackaby et al. 2005; David 2015; European Commission 2019; Purcell et al. 2004; Leemann 2010; Waaijer et al. 2016; Ward 2001).

While attaining high level of skills and qualifications is considered to be the key to economic and social prosperity (Purcell et al. 2004), there is evidence that the academic career path is becoming increasingly uncertain and precarious. As the number of $\mathrm{PhD}$ graduates increased over the past decades at a faster rate than the number of academic jobs, obtaining a tenure-track position has become ever more competitive, and a growing number of academics are employed on a temporary or fixed-term contract (Afonso 2016). It should be noted though, that the academic labour market is part of a larger labour market for doctorate recipients, who often seek alternative employment in the non-academic sector (Aanerud et al. 2007). Furthermore, existing job opportunities in the non-academic labour market may shape academic career outcomes and have differential implications for male and female graduates (Kulis et al. 2002). Therefore, the purpose of this study is to understand which factors contribute to the chances of obtaining a permanent position in the wider PhD labour market, and whether and how men and women differ in their career trajectories following doctoral graduation. 
Previous studies from Western countries have indicated that female academics are disadvantaged compared to their male peers across different stages of their career, including in the hiring process, promotion, obtaining research funding, and salary levels (Blackaby et al. 2005; European Commission 2019; Leemann 2010; Quadlin 2018; Ward 2001). For example, in a study of the academic labour market in Scotland, Ward (2001) found that male academics are more likely to be promoted at each stage of the academic job ladder, even after controlling for tenure, experience, career breaks, and productivity. Another study of academic economists in the United Kingdom has shown that women are not only disadvantaged in promotion, but also suffer from lower pay within each academic rank (Blackaby et al. 2005). Furthermore, the gender pay gap is not limited to academic positions; rather, it is consistent across other occupations held by doctoral graduates. For example, in a longitudinal study of doctorate recipients in the United States, Webber and Canché (2015) have shown that women consistently earned lower salaries than their male peers did across different employment sectors. Similarly, Purcell and colleagues (2004) found that among degree holders in the United Kingdom, males had higher earnings than their female peers, regardless of occupation cluster. However, despite evidence of gender disparities in the graduate labour market, less attention has been given to the aspect of job security among doctoral graduates and the role of gender in determining their likelihood of obtaining a permanent position in academia or elsewhere.

In the present study, we use data from the UK Doctoral Impact and Career Tracking Survey from 2013 (CFE Research 2017), to estimate the odds of men and women with a doctoral degree obtaining a permanent position within seven to nine years following graduation. In addition, we explore gender differences in obtaining a permanent job by study discipline, employment sector, and within and outside academia. In what follows, we review different theories on gender differences in career trajectories of higher education graduates (Section 2). In Section 3, we describe the data and methodology used in this study, followed by presentation of results in Section 4. A discussion of these findings in light of previous literature is included in Section 5.

\section{Gendered Career Pathways of Doctoral Graduates}

One of the central theories explaining women's disadvantage in their returns to higher education is the 'pipeline model', which was initially introduced by Berryman (1983) to account for the underrepresentation of women in science. According to this model, the entire trajectory of academic training and employment is shaped by gender stereotypes, which emphasize men's breadwinner role and women's traditional familial roles. These stereotypes not only shape the choice of study discipline, but also lead to the 'leakage' of women, who drop off at different stages of their career. Indeed, the career paths of women with doctorates tend to differ from those of men in several respects, such as field of study and sector of employment. For example, among postgraduate students in Europe and the United States, women are overrepresented in the arts, humanities, and subjects associated with the helping professions, while men are overrepresented in science, technology, engineering, and mathematics (STEM) subjects (European Commission 2019; Quadlin 2018). Thus, female PhD holders are more heavily concentrated in disciplines that offer fewer employment opportunities outside academia, while the opposite is true for their male counterparts (Kulis et al. 2002). Furthermore, in the UK and other Western countries, men are disproportionately more likely to work in the business enterprise sector, while women are more likely to work in the public sector and in the private non-profit sector (Purcell et al. 2004; Waaijer et al. 2016). In general, careers in business, or science and engineering, offer higher financial rewards than those in the humanities and social sciences (Higher Education Statistics Agency (Higher Education Statistics Agency) HESA). Hence, gender differences in the study discipline and employment sector further contribute to the gender pay gap. According to Waaijer et al. (2016), the combination of gender differences in the field of study, employment sector, and other employment characteristics has a cumulative effect, eventually leading to major gender gaps in the career trajectories of PhD graduates. 
Other studies have emphasized structural factors, including labour market conditions and the gendered division of labour in explaining career gaps among doctorate recipients. In the UK for instance, where there is limited state support for childcare, over a third of employed women work in a part-time job, which is recognized as a means of reconciling work and family responsibilities (Lewis et al. 2008). Moreover, as the division of unpaid work in the UK and elsewhere is highly gendered, and women are still expected to perform the bulk of household and child caring tasks, they are more likely to reduce their working hours than their male partners are, particularly when there are children in the household (Lewis et al. 2008; Sullivan 2019). The adverse consequences of family formation on women's career trajectories extend to academics as well; Wolfinger and colleagues (2008) have found that both marriage and children had independent negative effects on the likelihood of female PhD recipients in the United States to obtain tenure. Since female academics are more likely to be married or partnered with male academics, this may exacerbate the expectation from these women to forsake their own career in order to support the career of their partners (Baker 2016; Wolfinger et al. 2008). Moreover, women with family responsibilities, or those in a dual career relationship, often have limited ability to relocate in the pursuit of a tenure-track position (Leemann 2010; Wolfinger et al. 2008). This may pose a significant barrier for female doctoral graduates, as internationalization and mobility are becoming increasingly important for boosting competitiveness amongst academics, as well as among other highly skilled workers (Heijstra et al. 2017; Nikunen and Lempiäinen 2018). These barriers have also been found to influence women's decision on whether to pursue an academic career; in a study based in Canada, Van Anders (2004) has shown that considerations of parenthood and geographic mobility were more likely to have a negative influence on women's intentions to become professors than on those of their male peers. Furthermore, Waaijer and others (2016) have shown that female doctoral graduates have had a generally more negative view of their long-term career prospects, including availability of permanent employment in the academic and non-academic sectors, compared to their male counterparts. Thus, women are more likely to self-select themselves out from prestigious careers in academia or in other sectors.

In addition to these constraints, women may face direct discrimination and gender bias by employers when applying for a job or a promotion. For example, an audit study of job applications in the graduate labour market in the United States, found that high-achieving women are disadvantaged in the competition for lucrative positions. In this study, high-achieving women were evaluated less favourably by employers compared to either high- or low-achieving men and were less likely to receive a call back (Quadlin 2018). In addition, Weisshaar (2017) has found that women's disadvantage in receiving academic tenure remains even after accounting for productivity and variation in departmental context, which suggests an existing gender bias in promotional decisions. According to David (2015), due to persistent discrimination in the labour market, women do not receive the same returns on higher education as men do and are more likely to work in jobs where they do not use their skills.

In sum, gendered career trajectories of doctorate recipients are not merely a reflection of personal choices, rather, these pathways are also shaped by structural and normative constraints. These constraints include labour market conditions, gender role prescriptions, gender discrimination, and perceived career opportunities. In this context, it is hypothesized that female doctoral graduates are less likely to obtain a permanent position compared to their male counterparts, and that gendered differences in study discipline, employment sector, and other differential employment characteristics at least partly explain this gap.

\section{Data and Methods}

\subsection{Data and Sample}

The data for this study were drawn from the Doctoral Impact and Career Tracking Survey from 2013 (CFE Research 2017). The survey was commissioned by Research Councils UK (RCUK) and the higher education funding bodies for England and Wales (HEFCE and HEFCW), with the aim 
of exploring the career pathways, destinations, and impact of doctoral graduates over the medium to longer term. This survey builds on previous research of career pathways of doctoral graduates who qualified in 2004/05 and includes data from the Destinations of Leavers of Higher Education (DLHE) survey, which was carried out six months after graduation, and the longitudinal Destinations of Leavers of Higher Education (L_DLHE) survey, which was carried out around three and a half years after graduation. In 2013, these graduates were contacted again to be asked about their current activities. However, in order to boost the sample size, the existing data set also includes doctoral graduates who qualified in 2003/04 and in 2005/06. Therefore, the target population includes those who graduated with a doctorate degree from a UK higher education institution (HEI) from 2003/04 to $2005 / 06$.

Since there is no database for doctoral graduates, a volunteer sample of respondents was recruited with the majority of respondents (61\%) contacted via email or newsletter from alumni offices and careers centres at HEIs. Other respondents found out about the study through online promotion by CFE, professional societies, social media, and word of mouth. This resulted in a sample of 1839 respondents. Most responses were completed online, with a small number of cases completed via telephone. As the purpose of the current study is to examine the likelihood of obtaining a permanent position, the sample was restricted to respondents below the age of 60 , to exclude those in pension age (128 respondents aged 60 or above were removed as well as additional 31 respondents whose age was missing). In addition, only those who reported being employed in 2013 were included in the sample (133 were excluded). The sample was further reduced due to invalid answers or missing cases in other variables, leading to a sample size of 1150 respondents.

\subsection{Measures}

The dependent variable in this study was permanent employment status. This variable was based on a question about the basis of employment, which included six answer categories: 'On a permanent or open-ended contract', On a fixed-term contract lasting 12 months or longer', 'On a fixed-term contract lasting less than 12 months', 'Temporarily, through an agency', Temporarily, other than through an agency', and 'Employed on another basis'. As the outcome of interest was permanent employment, this variable was recoded into a binary variable, with the value of 1 if the respondent stated being employed on a permanent or open-ended contract and 0 otherwise. The independent variables included gender (coded 1 for female and 0 for male) and age group, divided into four categories: below 35, 35-39, 40-49, and 50-59 ${ }^{1}$. Another demographic measure was country of origin, which included three categories: United Kingdom, another European Union country, and other. This variable was chosen over the measure for ethnicity, since the latter has a large number of missing cases. In addition, we controlled for the subject of study. This measure followed the Higher Education Statistics Agency (HESA) categorization of study subjects and included the following categories: arts and humanities, social sciences, biological sciences, biomedical sciences, and physical sciences and engineering (see: CFE Research 2013) ${ }^{2}$. Additional measures for the type of employment included sector of employment, which includes private, public, and non-profit. About $1 \%$ of respondents did not know which employment sector they were affiliated with and were therefore excluded from the sample. In addition to employment sector, we also controlled for the occupational cluster, which is classified according to main occupations held by doctoral graduates. This includes higher education (HE) research, which refers to research staff from all study disciplines (e.g., natural and social science professionals), as well as HE teaching (all higher education teaching professionals, including HE professors, HE lecturers, and university tutorial and teaching assistants) and HE other (jobs in higher

1 The original age group variable included another group of under 30. However, due to the small number of cases in that group it is merged with the under-35 category.

2 Fourteen men and 24 women who obtained their degree in other subjects were excluded from the analysis due to small sample size. 
education other than research or teaching). Other categories included other research or teaching (all teaching professionals and researchers outside the higher education sector), and other doctoral occupations (this included common doctoral occupations, such as chief executive and senior officials, production managers and engineering, business or health professionals). The 'other occupations' cluster included artistic, literary and media occupations, sales and marketing, and other roles (ibid.). Finally, as gender differences are also evident in working hours, we included a measure denoting whether the respondent was employed on a full-time or a part-time basis.

\subsection{Analytical Strategy}

The first part of the analysis included descriptive statistics of the study sample, followed by analysis of gender differences in obtaining a permanent contract by study discipline, employment sector, occupation cluster (academic/non-academic), and working hours. In addition, using linked data from the DLHE and the L_DLHE surveys, we estimated the proportion of male and female doctoral graduates who were employed in a permanent contract six months, three and a half years, and seven to nine years after graduations. This was done in order to gain insight about gendered differences in securing a permanent position across different career stages of doctorate recipients. Then, we ran a multivariate logistic regression analysis to estimate the extent to which gender was associated with the likelihood of obtaining a permanent position while controlling for other socio-demographic factors and employment characteristics. The regression analysis was done using nested models, where variables were gradually added to the model in order to understand which factors may moderate the relationship between gender and obtaining a permanent job and to test whether there is a cumulative effect of differential employment characteristics of male and female doctoral graduates.

\section{Results}

Table 1 presents the sample characteristics of doctoral graduates at the time of the survey in 2013, seven to nine years following graduation. The sample included 466 women and 684 men. Men were slightly overrepresented in this sample, as they still form a majority of doctoral students. In addition, including only those under the age of 60 and excluding those who are not in paid work further contributed to the higher proportion of men in the study sample. Nearly $80 \%$ of doctoral graduates in our sample obtained a permanent job within seven to nine years after graduation, although the proportion of those with a permanent position was lower for women than it was for men $(75 \%$ and $82 \%$, respectively). The proportion of respondents with fixed-term or temporary employment was higher compared to the proportion of temporary workers in the UK, which stands at $5 \%-6 \%$ of all employees (Office for National Statistics 2019). In terms of age distribution, the largest age group was 35-39 (41\%), while just over a quarter of graduates were below the age of 35 , one-fifth of graduates were 40-49 years old, and just over a tenth were 50-59 years old. Women in the sample were slightly older than men, although this difference was not significant. Men and women however differed greatly by the study discipline in which they obtained their degree. Thus, half of the male respondents obtained their doctorate in physical sciences and engineering, compared to only a quarter of the female respondents. Women were more likely to obtain their degree in the arts and humanities, social sciences and also in biomedical studies than men do. This is in line with the gender distribution of study discipline among those who have recently completed a postgraduate degree in the UK (see Appendix A). The majority of male and female respondents were originally from the UK, whereas $11 \%$ were from another EU country and $15 \%$ were from other countries. In addition, most graduates $(70 \%)$ were currently working in the UK and the rest were working abroad. It should be noted that a higher proportion of male graduates were working abroad compared to female graduates, which is in line with the literature on the greater limitations on geographical mobility experienced by female graduates (Leemann 2010; Wolfinger et al. 2008). 
Table 1. Sample characteristics of doctoral graduates in 2013 (seven to nine years post-graduation).

\begin{tabular}{|c|c|c|c|c|c|c|c|}
\hline \multirow[b]{2}{*}{ List of Variables } & \multirow[b]{2}{*}{ Categories } & \multicolumn{2}{|c|}{ Men } & \multicolumn{2}{|c|}{ Women } & \multicolumn{2}{|c|}{ Total } \\
\hline & & $\mathbf{n}$ & $\%$ & $\mathbf{n}$ & $\%$ & $\mathbf{n}$ & $\%$ \\
\hline \multirow{2}{*}{ Contract type } & Permanent & 562 & 82 & 348 & 75 & 910 & 79 \\
\hline & Fixed-term/Temporary & 122 & 18 & 118 & 25 & 240 & 21 \\
\hline \multirow{4}{*}{ Age group } & $<35$ & 203 & 30 & 120 & 26 & 323 & 28 \\
\hline & $35-39$ & 277 & 40 & 191 & 41 & 468 & 41 \\
\hline & $40-49$ & 127 & 19 & 107 & 23 & 234 & 20 \\
\hline & $50-59$ & 77 & 11 & 48 & 10 & 125 & 11 \\
\hline \multirow{5}{*}{ Study discipline } & Arts and humanities & 73 & 11 & 89 & 19 & 162 & 14 \\
\hline & Social sciences & 90 & 13 & 73 & 16 & 163 & 14 \\
\hline & Biological sciences & 115 & 17 & 80 & 17 & 195 & 17 \\
\hline & Biomedical sciences & 64 & 9 & 105 & 22 & 169 & 15 \\
\hline & Physical sci/Engineering & 342 & 50 & 119 & 26 & 461 & 40 \\
\hline \multirow{3}{*}{ Country of origin } & United Kingdom & 492 & 72 & 365 & 78 & 857 & 74 \\
\hline & EU country & 75 & 11 & 47 & 10 & 122 & 11 \\
\hline & Other & 117 & 17 & 54 & 12 & 171 & 15 \\
\hline \multirow{2}{*}{ Country of employment } & United Kingdom & 443 & 65 & 363 & 78 & 806 & 70 \\
\hline & Other & 241 & 35 & 103 & 22 & 344 & 30 \\
\hline \multirow{3}{*}{ Employment sector } & Public & 402 & 59 & 342 & 73 & 744 & 65 \\
\hline & Private & 248 & 36 & 92 & 20 & 340 & 29 \\
\hline & Non-profit & 34 & 5 & 32 & 7 & 66 & 6 \\
\hline \multirow{6}{*}{ Occupation cluster } & HE teaching & 200 & 29 & 182 & 39 & 382 & 33 \\
\hline & HE research & 83 & 12 & 66 & 14 & 149 & 13 \\
\hline & HE other & 28 & 4 & 41 & 9 & 69 & 6 \\
\hline & Other research/teaching & 115 & 17 & 69 & 15 & 184 & 16 \\
\hline & Other doctoral occupations & 180 & 26 & 62 & 13 & 242 & 21 \\
\hline & Other occupations & 78 & 12 & 46 & 10 & 124 & 11 \\
\hline \multirow{3}{*}{ Working hours } & Full-time & 664 & 97 & 372 & 80 & 1036 & 90 \\
\hline & Part-time & 20 & 3 & 94 & 20 & 114 & 10 \\
\hline & Total & 684 & 100 & 466 & 100 & 1150 & 100 \\
\hline
\end{tabular}

More than half of the graduates were working in the HE sector, either in teaching (33\%), research $(13 \%)$, or other roles $(6 \%)$. A fifth were working in other common doctoral occupations, less than a fifth engaged in research or teaching outside academia, and about a tenth of graduates were working in other occupations. Women were more likely to work in academia compared to men, while a higher proportion of men were working in doctoral occupations outside academia, which included management and engineering occupations. Furthermore, nearly all male graduates were working in a full-time job (97\%) compared to only $80 \%$ of female graduates. Women's part-time work has become normalized in the UK, as not only mothers of young children are working this way, but also a relatively high share of all women work part-time (Lewis 2012). Furthermore, since the 2000s, the legal right to request flexible working was introduced, which further increased the option of working reduced hours (Vlasblom and Schippers 2006). It should be noted though, that flexible and part-time working arrangements are much more common in the public than in the private sector (Beatson 2019).

As gender differences in study discipline and other employment characteristics may be responsible for some of the discrepancies between men and women in their career trajectories, we explored the proportion of men and women in permanent employment for each of these factors.

Figure 1 shows the proportion of doctoral graduates with a permanent position by gender and study discipline. It was shown that women were less likely to hold a permanent position compared to men among doctoral graduates in biological and biomedical studies as well as among those who 
studied arts and humanities. However, these differences were only significant for biological sciences, where $61 \%$ of women were in permanent employment compared to $76 \%$ of men.

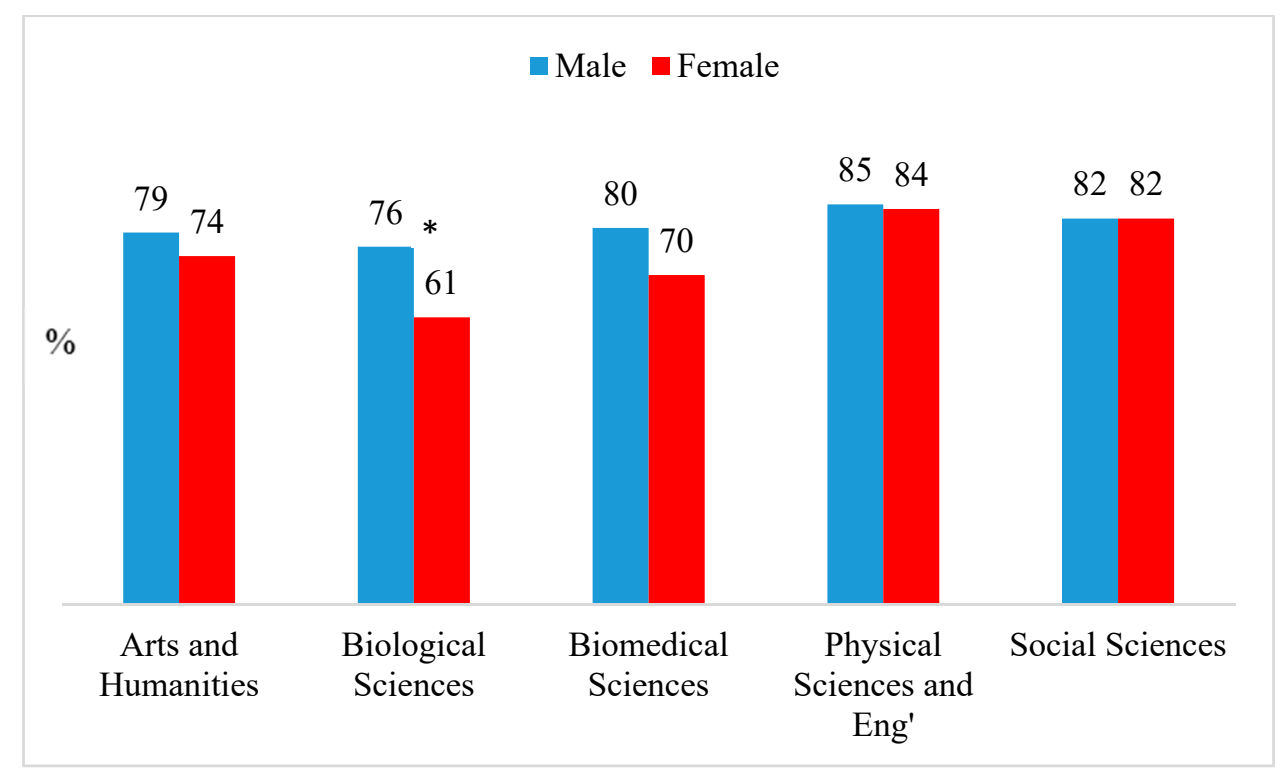

Figure 1. Proportion of doctoral graduates with a permanent job by gender and study discipline in $2013\left({ }^{*} p<0.5\right)$.

When looking at gender differences in permanent employment by sector of employment (Figure 2), it was shown that in both the public and private sectors women were less likely to work in a permanent contract than men were, although the difference was much more significant within the private sector ( $94 \%$ of men compared to $84 \%$ of women are in permanent employment) than in the public sector $(76 \%$ of men and $71 \%$ of women in permanent employment). Interestingly, women were more likely to have a permanent employment than men within the third sector ( $88 \%$ compared to $68 \%$ respectively), although this difference was not significant. Furthermore, when comparing gender differences in permanent employment by occupation cluster (academic vs. non-academic jobs), it appeared that the gender gap was considerably smaller within academia than outside it; within academia $72 \%$ of men were permanently employed compared to $69 \%$ of women, while the parallel figures for non-academic jobs were $91 \%$ and $84 \%$ (see Figure 3). It is possible that greater regulation of recruitment processes in academic institutions (as well as among other employers in the public sector) has contributed to the smaller gender gap in permanent employment. According to Blackaby et al. (2005), unlike salary scales, which are negotiated individually, academic appointments in UK universities are subject to well-defined procedures and approvals from relevant committees. This, in turn, can lead to reduced gender differences in the basis of employment for academic jobs. This finding is in accordance with a recent study by Webber and Canché (2018), who did not find significant differences by gender in obtaining tenure among doctorate recipients in the United States, despite evidence of lower salary for women in academia. It should be noted though, that in non-academic occupations women were significantly less likely to be employed on a permanent contract compared to men. 


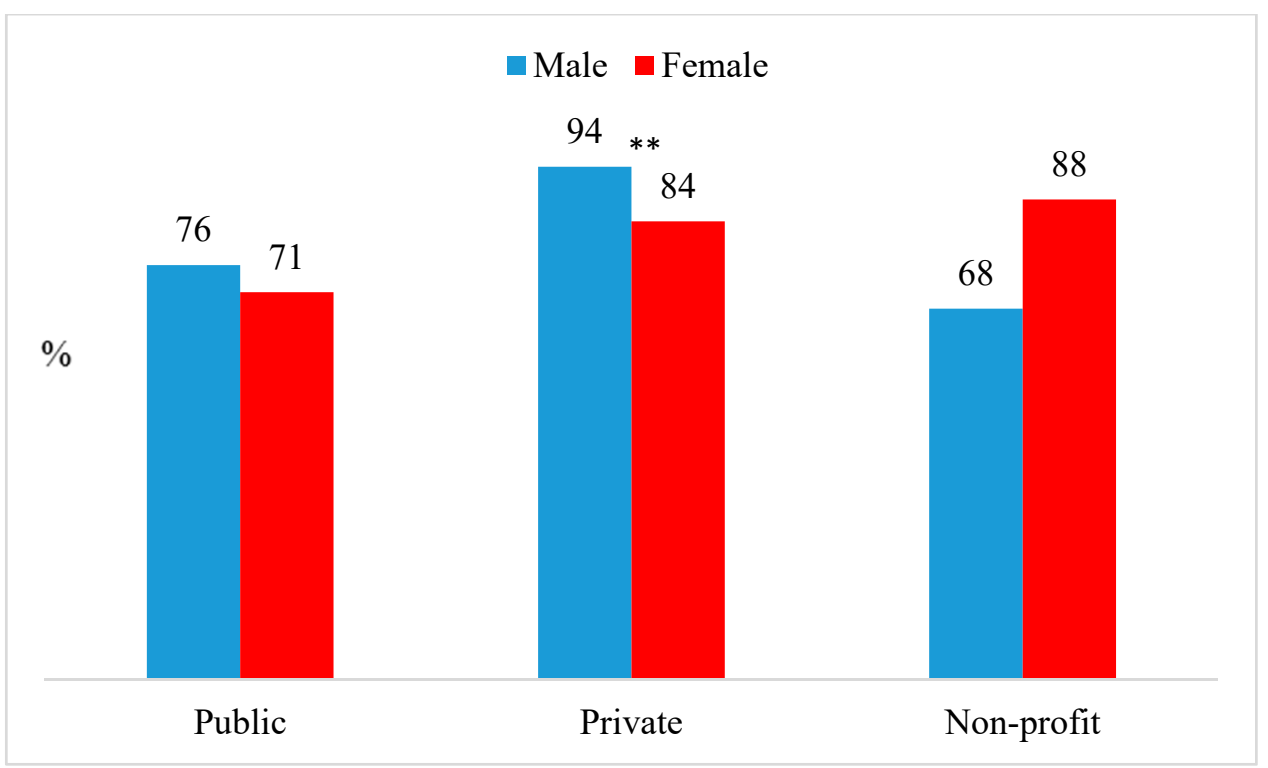

Figure 2. Proportion of doctoral graduates with a permanent job by gender and employment sector in $2013\left({ }^{* *} p<0.01\right)$.

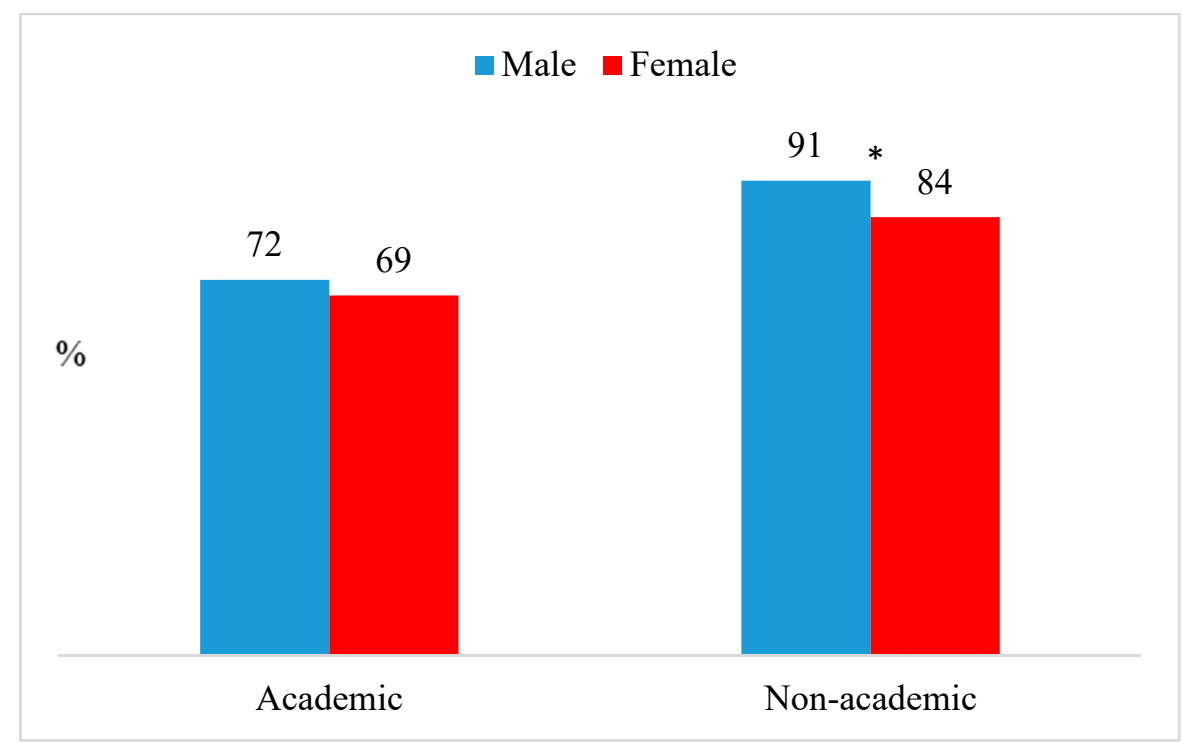

Figure 3. Proportion of doctoral graduates with a permanent job by gender and occupation cluster in $2013\left({ }^{*} p<0.5\right)$.

Another major difference in employment patterns of male and female doctoral graduates was in working hours. Figure 4 shows the proportion of male and female graduates with a permanent job divided by those in full-time and in part-time employment. This figure shows that women's disadvantage in holding a permanent position remains significant also among those working full-time. Interestingly, the proportion of women with a permanent contract among those who work part-time was higher than that of men, although this difference was not significant.

Next, we explore gender differences in permanent employment at different career stages following graduation. Figure 5 displays the proportion of male and female doctoral graduates who obtained a permanent position in different time periods following their graduation. It appears that in any stage following graduation, men were significantly more likely to work in a permanent contract than women were; six months after graduation, just over half of male graduates were employed in a permanent position compared to $41 \%$ of female graduates. This gap increases further in the next period of three 
and a half years following graduations to $74 \%$ and $61 \%$, respectively. In the most recent time period of seven to nine years following graduation, the gender gap had slightly decreased, so that $82 \%$ of males and $75 \%$ of females were in permanent employment during that time. Nevertheless, this gap remained significant. Moreover, as this figure shows, male doctoral graduates were not only more likely to obtain a permanent position than their female peers, but they also tended to achieve it more quickly after graduation ${ }^{3}$.

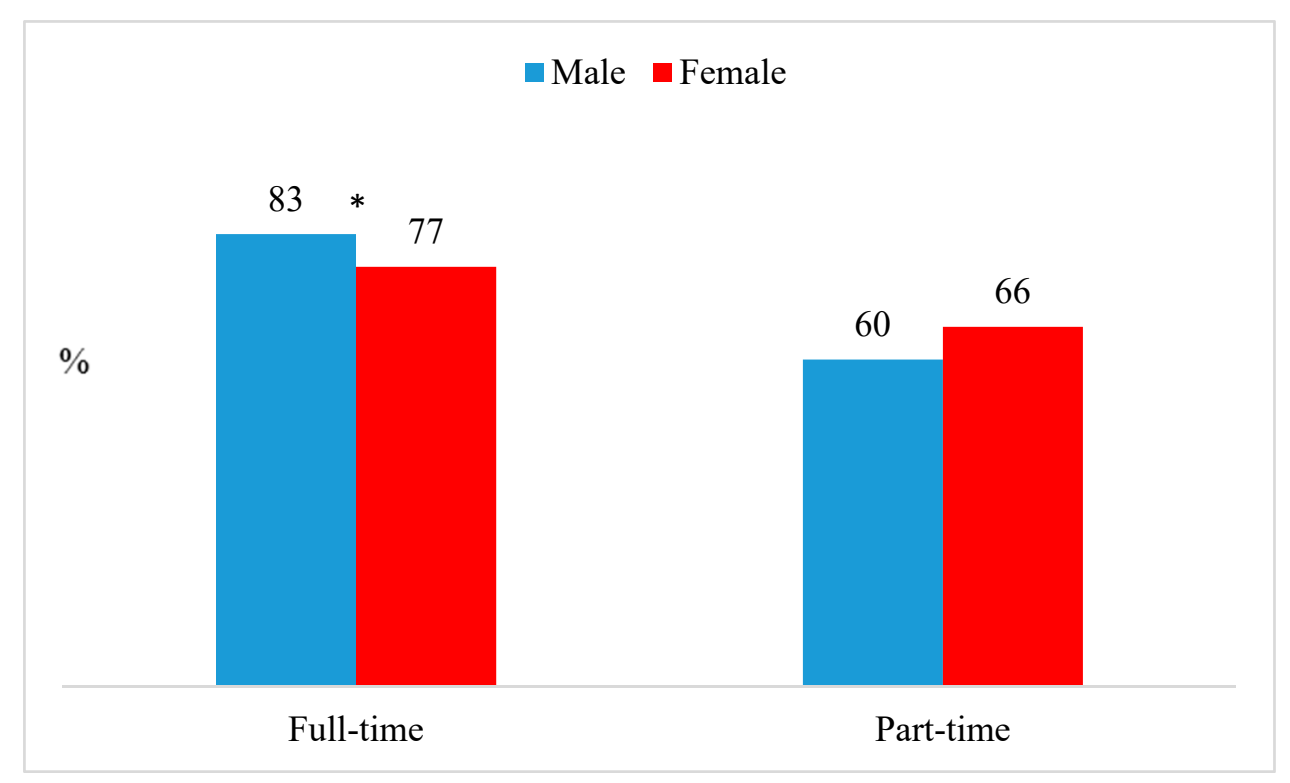

Figure 4. Proportion of doctoral graduates with a permanent job by gender and working hours in 2013 $\left({ }^{*} p<0.5\right)$.

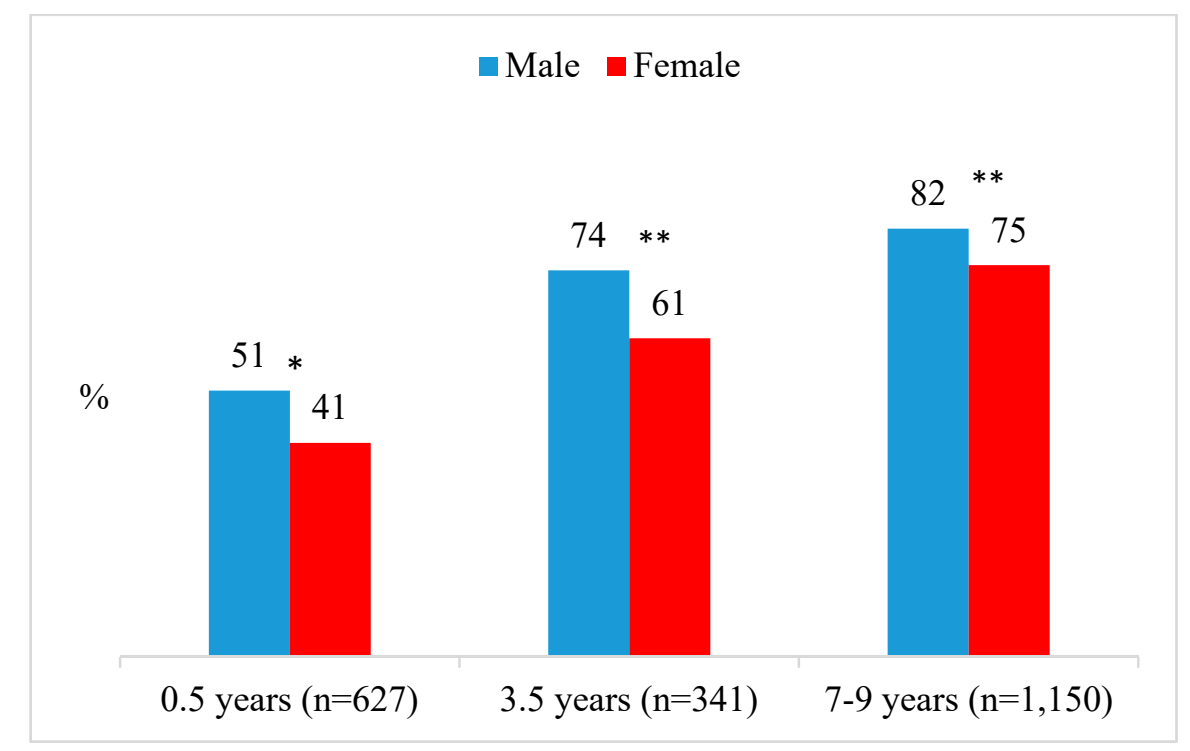

Figure 5. Proportion of doctoral graduates with a permanent position by gender and time elapsed since graduation $\left({ }^{*} p<0.5,{ }^{* *} p<0.01\right)$.

3 While this comparison is based on different sample sizes, the results are qualitatively the same when using a balanced sample for the different time periods. 
In order to gain a better understanding of how gender is associated with permanent employment and the potential intervening factors in this relationship, we ran a multivariate logistic regression model, which is presented in Table 2; the first model in the regression introduces basic demographic characteristics, including gender, age, country of origin, country of employment, and study discipline. It was shown that when these factors are held constant, the odds of female doctoral graduates obtaining a permanent job were about two thirds of the odds for males $(\mathrm{OR}=0.673$, significant at $p<0.05$, see: Table 2, Model 1).

Table 2. Logistic regression analysis model for permanent employment (odds ratios).

\begin{tabular}{|c|c|c|c|c|}
\hline & & Model 1 & Model 2 & Model 3 \\
\hline \multirow[t]{2}{*}{ Gender } & Female & 0.673 * & 0.634 * & 0.774 \\
\hline & Male (ref.) & 1.000 & 1.000 & 1.000 \\
\hline \multirow[t]{4}{*}{ Age group } & $<35$ & $0.542 * *$ & 0.705 & 0.641 * \\
\hline & 35-39 (ref.) & 1.000 & 1.000 & 1.000 \\
\hline & $40-49$ & 0.888 & 1.082 & 1.082 \\
\hline & $50-59$ & 1.242 & 1.776 & 1.969 * \\
\hline \multirow[t]{5}{*}{ Study discipline } & Arts and Humanities (ref.) & 1.000 & 1.000 & 1.000 \\
\hline & Social sciences & 1.368 & 1.648 & 1.548 \\
\hline & Biological sciences & 0.771 & 1.166 & 1.019 \\
\hline & Biomedical sciences & 0.891 & 1.354 & 1.347 \\
\hline & Physical sci/Engineering & $1.801 *$ & $2.336^{* *}$ & $2.184^{* *}$ \\
\hline \multirow[t]{3}{*}{ Country of origin } & United Kingdom (ref.) & 1.000 & 1.000 & 1.000 \\
\hline & EU country & 0.901 & 0.934 & 0.905 \\
\hline & Other & 1.491 & 1.698 & 1.650 \\
\hline \multirow{2}{*}{ Country of employment } & United Kingdom (ref.) & 1.000 & 1.000 & 1.000 \\
\hline & Other & $0.543^{* *}$ & $0.330^{* * *}$ & $0.303^{* * *}$ \\
\hline \multirow{3}{*}{ Employment sector } & Public (ref.) & & 1.000 & 1.000 \\
\hline & Private & & $2.467^{* *}$ & $2.534^{* * *}$ \\
\hline & Non-profit & & 0.750 & 0.693 \\
\hline \multirow{6}{*}{ Occupation cluster } & HE research & & $0.043^{* * *}$ & $0.043^{* * *}$ \\
\hline & HE teaching (ref.) & & 1.000 & 1.000 \\
\hline & HE other & & 0.782 & 0.874 \\
\hline & Other research/teaching & & 0.655 & 0.683 \\
\hline & Other doctoral occupations & & 0.905 & 0.969 \\
\hline & Other occupations & & 1.227 & 1.281 \\
\hline \multirow[t]{4}{*}{ Working hours } & Full-time (ref.) & & & 1.000 \\
\hline & Part-time & & & $0.320^{* * *}$ \\
\hline & Pseudo $\mathrm{R}^{2}$ & 0.048 & 0.268 & 0.282 \\
\hline & $\mathbf{N}$ & 1150 & 1150 & 1150 \\
\hline
\end{tabular}

Despite major differences by gender in the sector of employment and occupation cluster, when these covariates were added to the model, the female coefficient was practically unaffected (Table 2, Model 2). Therefore, the disadvantage of women in obtaining permanent employment cannot be explained by the choice of employment sector or type of occupation. However, when controlling for working hours (full-time/part-time employment), the relationship between gender and permanent employment status was no longer significant (Table 2, Model 3). As shown in this model, there was a strong negative correlation between part-time employment and working in a permanent contract $(\mathrm{OR}=0.320$, significant at $p<0.001)$. Interestingly, while the gender difference in working hours could not account by itself for the gender gap in securing a permanent contract, it appeared to have a cumulative 
effect in relation to women's odds of obtaining a permanent employment when combined with other employment characteristics ${ }^{4}$.

Other relevant findings included the lower likelihood of graduates under the age of 35 to obtain a permanent position compared to that of those aged 35-39. This could be explained by the fact that doctoral graduates under the age of 35 are less likely to have gained sufficient work experience that is required either for the academic or non-academic job market.

The subject of study is also an important predictor of permanent employment; as our analysis shows the odds of obtaining a permanent job among those who studied physical sciences and engineering were twice as high as for those who have a doctoral degree in the arts and humanities. This may be due to wider employment opportunities in the former, both in academia and the industry. It was also shown that those working abroad were significantly less likely to work in a permanent contract. As transnational mobility became "an indispensable element in the career trajectory, especially of early career researchers" (Leemann 2010, p. 611), it is possible that some doctoral graduates travel to work abroad for purposes of career development, even for temporary employment.

In terms of employment sector, those who work in the public sector or in a non-profit organization were less likely to have a permanent contract than those who are employed in the private sector. As the majority of higher education institutions are publicly funded, this finding may reflect the difficulty of obtaining a permanent job in academia. Furthermore, those who were employed in HE research jobs were significantly less likely to have a permanent contract than those working in HE teaching. This reflects the fact that many of the available academic research jobs, particularly post-doctoral positions, are only offered on a fixed-term basis (Afonso 2016; Xing et al. 2019). According to Afonso (2016), the current funding system of universities in the UK, which is closely tied to academic performance, provides strong incentives for university departments to hire researchers with a competitive publication record. As a result, the transition from $\mathrm{PhD}$ to a permanent position in academia is particularly difficult, and many doctoral graduates are employed in temporary or flexible contracts.

\section{Discussion}

This study explored gendered differences in career trajectories of doctoral graduates, who earned their degree in a UK higher education institution from 2003/04 to 2005/06. In particular, we focused on gender disparities in the odds of obtaining a permanent position. As this study shows, one in five doctoral graduates in our sample were employed in either a fixed-term or a temporary contract seven to nine years after earning their degree, although the proportion of female graduates with a permanent position was significantly lower than that of male graduates ( $75 \%$ compared to $82 \%$, respectively). The lower proportion of female graduates in permanent employment was evident both in the short-term (six months and 3.5 years after graduation) and in the longer term (7-9 years after graduation). When exploring gender differences in permanent employment by sector and occupation type, it appears that these disparities are more significant in private organizations than in the public sector and in non-academic occupations than within academia. Therefore, while there is consistent evidence for a gender pay gap in the academic job market (Blackaby et al. 2005; European Commission 2019; Ward 2001), gender differences in obtaining a permanent position in academia appear to be less pronounced. This may be due to the relatively regulated process of academic hiring in the UK. In addition, it could point to narrowing gender gaps in academia, at least in terms of acquiring tenure, as suggested by Webber and Canché (2018). Nevertheless, in aggregate terms, female doctoral graduates are significantly less likely to obtain a permanent position compared to their male peers.

4 Additional models were estimated to detect for interactions between gender and other characteristics, including study discipline, sector of employment, occupation cluster, and working hours. However, none of these interactions were significant. 
Furthermore, when comparing doctoral graduates on the basis of working hours, it was found that the gender gap in permanent employment was consistent among those in full-time employment.

The results from the multivariate regression analysis confirmed that most background and job characteristics factors that were linked with the odds of securing a permanent job, such as study discipline, sector of employment, and occupational cluster, did not explain the observed disadvantage of female graduates. However, when working hours were added to the model, gender differences became insignificant.

Part-time work is a relatively common option among working mothers in the UK, as it offers a way of combining paid employment with family responsibilities (Lewis et al. 2008). However, part-time employment often has detrimental effects on career trajectories, including lower pay and limited opportunities for promotion (Baizán 2007). The higher propensity of female doctoral graduates to work in part-time employment may also be due to additional challenges they encounter when pursuing stable employment in the highly competitive graduate job market, including the requirement for geographical mobility, or gender discrimination. Furthermore, since female doctoral graduates are concentrated in fields that offer relatively fewer employment opportunities outside academia (e.g., humanities, social sciences and life sciences), they have more limited career options compared to their male peers, and these options may be further restricted when seeking part-time or flexible work. As this study shows, while reduced working hours by itself did not explain women's disadvantage in obtaining a permanent position, the combination of part-time work with other differential career pathways (i.e., study discipline and employment sector), accounted for the observed gender gap in achieving permanent employment among doctoral graduates.

Finally, it is important to note several limitations of the current research. One of the shortcomings of the data set used in this study was lack of information about respondents' marital and parental status. Therefore, it is difficult to assess the role of family structure on the career pathways of respondents in this study. In addition, since most measures relating to job characteristics were only available for those who were in paid work at the time of the survey, the analysis excluded unemployed and economically inactive respondents. Nevertheless, this study sheds light on gender differences in career trajectories among highly skilled individuals in the UK and the mechanisms underlying the lower propensity of female doctoral graduates to obtain permanent employment.

Future research should explore the differential influence of family responsibilities on career trajectories of male and female doctoral graduates, as well as the gendered pattern of self-selection into different types of jobs following graduation from higher education institutions. In addition, further research should be done on gender differences in career opportunities of doctoral graduates in the private sector, as gender discrepancies are particularly marked in private sector organizations.

While hiring and promotion procedures are relatively regulated in academia and the public sector, private sector organizations are not subject to similar accountability. Therefore, there should be greater incentives through tax benefits or other forms of state support to those organizations that promote equal gender representation across different ranks. In addition, higher education institutions should be encouraged to expand the supply of permanent positions over fixed-term contracts, in order to retain high quality male and female employees.

Funding: This research received no external funding.

Conflicts of Interest: The author declares no conflict of interest. 


\section{Appendix A. Distribution of Obtained Postgraduate Research Degrees by Gender and Study Discipline in the UK (2017/18)}

Table A1. Adapted from: Higher Education Students Statistics (HESA), 2019. (HESA 2017).

\begin{tabular}{ccccccc}
\hline & \multicolumn{2}{c}{ Men } & \multicolumn{2}{c}{ Women } & \multicolumn{2}{c}{ Total } \\
\hline Study Discipline & $\mathbf{n}$ & $\mathbf{\%}$ & $\mathbf{n}$ & $\mathbf{\%}$ & $\mathbf{n}$ & $\mathbf{\%}$ \\
\hline Arts and humanities & 2210 & 15 & 2320 & 18 & 4530 & 16 \\
Social sciences & 2285 & 15 & 2175 & 17 & 4460 & 16 \\
Biological sciences & 1730 & 11 & 2620 & 20 & 4350 & 15 \\
Biomedical sciences & 1995 & 13 & 2770 & 22 & 4765 & 17 \\
Physical sci/Engineering & 7025 & 46 & 2975 & 23 & 10,000 & 36 \\
\hline Total & $\mathbf{1 5 , 2 4 5}$ & $\mathbf{1 0 0}$ & $\mathbf{1 2 , 8 6 0}$ & $\mathbf{1 0 0}$ & $\mathbf{2 8 , 1 0 5}$ & $\mathbf{1 0 0}$ \\
\hline
\end{tabular}

\section{References}

Aanerud, Rebecca, Emory Morrison, Lori Homer, Elizabeth Rudd, Maresi Nerad, and Joseph Cerny. 2007. Widening the lens on gender and tenure: Looking beyond the academic labor market. NWSA Journal 19: 105-23. Available online: http://www.jstor.org/stable/40071231 (accessed on 15 November 2019).

Afonso, Alexandre. 2016. Varieties of academic labor markets in Europe. PS: Political Science E Politics 49: 816-21. [CrossRef]

Baizán, Pau. 2007. The impact of labour market status on second and higher-order births. In Family Formation and Family Dilemmas in Contemporary Europe. Edited by Gosta Esping-Andersen. Bilbao: Fundación BBVA, pp. 93-127.

Baker, Maureen. 2016. Women graduates and the workplace: Continuing challenges for academic women. Studies in Higher Education 41: 887-900. [CrossRef]

Beatson, Mark. 2019. Mega Trends: Flexible Working. London: Chartered Institute of Personnel and Development, Available online: https://www.cipd.co.uk/Images/megatrends-report-flexible-working-1_tcm18-52769.pdf (accessed on 15 October 2019).

Berryman, Sue E. 1983. Who Will Do Science? Trends, and Their Causes in Minority and Female Representation among Holders of Advanced Degrees in Science and Mathematics. A Special Report. New York: Rockefeller Foundation.

Blackaby, David, Alison L. Booth, and Jeff Frank. 2005. Outside offers and the gender pay gap: Empirical evidence from the UK academic labour market. The Economic Journal 115: F81-F107. Available online: http://www.jstor.org/stable/3590464 (accessed on 15 November 2019). [CrossRef]

CFE Research. 2013. Survey Data User Guide: The Impact of Doctoral Careers. Leicester: CFR Research.

CFE Research. 2017. Doctoral Impact and Career Tracking Survey, 2013. [Data Collection]. UK Data Service. SN: 8259. Available online: http://doi.org/10.5255/UKDA-SN-8259-1 (accessed on 15 November 2019).

David, Miriam E. 2015. Women and gender equality in higher education? Education Science 5: 10-25. [CrossRef]

European Commission. 2019. She Figures 2018. Luxembourg: Publications Office of the European Union, Available online: https://www.etag.ee/wp-content/uploads/2019/03/She-Figures-2018-1.pdf (accessed on 15 November 2019).

Heijstra, Thamar Melanie, Finnborg Salome Steinthorsdóttir, and Thorgerdur Einarsdóttir. 2017. Academic career making and the double-edged role of academic housework. Gender and Education 29: 764-80. [CrossRef]

HESA. 2017. Figure 18-HE Qualifications Obtained by Subject Area and Sex. Statistical Bulletin 252. Available online: https://www.hesa.ac.uk/data-and-analysis/sb252/figure-18 (accessed on 15 November 2019).

Higher Education Statistics Agency (HESA). 2018. Higher Education Leavers Statistics: UK, 2016/2017. Available online: https://www.hesa.ac.uk/news/28-06-2018/sfr250-higher-education-leaver-statistics-employment (accessed on 9 October 2019).

Kulis, Stephen, Diane Sicotte, and Shawn Collins. 2002. More than a pipeline problem: Labor supply constraints and gender stratification across academic science disciplines. Research in Higher Education 43: 657-91. [CrossRef]

Leemann, Regula Julia. 2010. Gender inequalities in transnational academic mobility and the ideal type of academic entrepreneur. Discourse: Studies in the Cultural Politics of Education 31: 605-25. [CrossRef] 
Lewis, Jane. 2012. Gender equality and work-family balance in a cross-national perspective. In Gendered Lives: Gender Inequalities in Production and Reproduction. Edited by Jacqueline Scott, Shirley Dex and Anke C. Plagnol. Cheltenham: Edward Elgar Publishing Limited, pp. 206-24.

Lewis, Jane, Mary Campbell, and Carmen Huerta. 2008. Patterns of paid and unpaid work in Western Europe: Gender, commodification, preferences and the implications for policy. Journal of European Social Policy 18: 21-37. [CrossRef]

Nikunen, Minna, and Kirsti Lempiäinen. 2018. Gendered strategies of mobility and academic career. Gender and Education. [CrossRef]

Office for National Statistics. 2019. Statistical Bulletin: Labour Market Overview, UK: June 2019. Available online: https:/www.ons.gov.uk/employmentandlabourmarket/peopleinwork/ employmentandemployeetypes/bulletins/uklabourmarket/june2019 (accessed on 15 November 2019).

Purcell, Kate, Peter Elias, and Nick Wilton. 2004. Higher Education, Skills and Employment: Careers and Jobs in the Graduate Labour Market. Researching Graduate Careers Seven Years On. Research Paper No. 3. University of West of England, Warwick Institute for Employment and Research, Coventry, UK.

Quadlin, Natasha. 2018. The mark of a woman's record: Gender and academic performance in hiring. American Sociological Review 83: 331-60. [CrossRef]

Sullivan, Oriel. 2019. Gender inequality in work-family balance. Nature Human Behaviour 3: 201-3. [CrossRef]

Van Anders, Sari M. 2004. Why the academic pipeline leaks: Fewer men than women perceive barriers to becoming professors. Sex Roles 51: 511-21. [CrossRef]

Van Bavel, Jan. 2012. The reversal of gender inequality in education, union formation and fertility in Europe. Vienna Yearbook of Population Research 10: 127-54. Available online: http://www.jstor.org/stable/41941000 (accessed on 15 November 2019). [CrossRef]

Vlasblom, Jan Dirk, and Joop Schippers. 2006. Changing dynamics in female employment around childbirth: Evidence from Germany, the Netherlands and the UK. Work, Employment and Society 20: 329-47. [CrossRef]

Waaijer, Cathelijn J. F., Hans Sonneveld, Simone E. Buitendijk, Cornelis A. van Bochove, and Inge C. M. van der Weijden. 2016. The role of gender in the employment, career perception and research performance of recent PhD graduates from Dutch Universities. PLOS ONE 11: e0164784. [CrossRef]

Ward, Melanie E. 2001. Gender and promotion in the academic profession. Scottish Journal of Political Economy 48: 283-302. [CrossRef]

Webber, Karen L., and Manuel González Canché. 2015. Not equal for all: Gender and race differences in salary for doctoral degree recipients. Research in Higher Education 56: 645-72. [CrossRef]

Webber, Karen L., and Manuel González Canché. 2018. Is there a gendered path to tenure? A multi-state approach to examine the academic trajectories of U.S. doctoral recipients in the sciences. Research in Higher Education 59: 897-932. [CrossRef]

Weisshaar, Katherine. 2017. Publish and perish? An assessment of gender gaps in promotion to tenure in academia. Social Forces 96: 529-60. [CrossRef]

Wolfinger, Nicholas H., Mary Ann Mason, and Marc Goulden. 2008. Problems in the pipeline: Gender, marriage, and fertility in the Ivory Tower. The Journal of Higher Education 79: 388-405. [CrossRef]

Xing, Yanmeng, An Zeng, Ying Fan, and Zengru Di. 2019. The strong nonlinear effect in academic dropout. Scientometrics 120: 793-805. [CrossRef]

(C) 2019 by the author. Licensee MDPI, Basel, Switzerland. This article is an open access article distributed under the terms and conditions of the Creative Commons Attribution (CC BY) license (http://creativecommons.org/licenses/by/4.0/). 